\title{
EDITORIAL
}

\section{The effective OR group}

Most managers do not see OR as an essential part of their organization's operations - it is not a core function. This is something that can easily be forgotten by practitioners, particularly in OR groups which have been around for some time and even expanded over the years. In these circumstances, many $O R$ groups could be forgiven for becoming complacent about their security of tenure. Yet the dangers are real enough. The recent dispanding of the OR group in a well-known company, apparently as part of a cost-cutting exercise, serves as a sharp reminder of the potential vulnerability of the $O R$ function. It would be instructive to examine the rationale of such a decision, for there must be lessons here for practitioners everywhere.

Two plausible explanations are that either the OR activity was not considered to be sufficiently costeffective, or that most, if not all, of the OR work could be continued by other parts of the organization.

Clearly, OR should be nothing if not cost-effective. Yet measuring cost-effectiveness may not be easy. In theory at least, project-related costs are relatively easy to identify in terms of staff time, departmental fixed costs and company overheads, although practical difficulties abound. (How many practitioners include the cost of client staff time in evaluating the total cost of a project?) The difficulties of identifying the benefits of OR interventions are widely acknowledged. Not least among these difficulties are identifying the kinds of benefit derived and quantifying them. For example: what are the benefits that accrue from a new or enhanced decisionsupport system? Benefits may ripple out through the organization from the client's department, they may accumulate over a period of time, and they may be perceived differently by different parts of the organization. An intervention which provides a client with improvements in efficiency and greater (centralized) control over operations may be viewed by others as an undesirable loss of flexibility and an increase in bureaucracy. Even where the nature of the benefit is clear-cut and expressable in financial terms, the size of the savings may not be. A fundamental difficulty lies in not knowing what action would have been taken in the absence of OR support. Given all of these problems, plus pressures to get on with the next project, it is small wonder that gauging "customer satisfaction" is as far as ex-post assessment of benefits actually gets for many projects. In terms of maintaining a steady flow of work in stable conditions, this approach is fine. However, in justifying expansion of OR activity, or even retention of activity, this approach may not be adequate. Hard evidence of cost-effectiveness may be needed.
Whatever the evidence of cost-effectiveness available, it is in the interest of any in-house OR group actively to manage organizational perceptions of the costeffectiveness of OR. Being cost-effective may not be nearly as important as appearing to be so. Management throughout the organization, particularly senior management, need to have an accurate perception of the contribution made by the OR function to organizational performance.

Of course, much depends on the type of projects undertaken. This in turn depends on a variety of factors, not least of which are the location of the OR function in the organization structure and management perceptions of the types of contribution OR can make. Like any business planning strategically, OR groups need consciously to manage the structure of their project portfolio. An obvious issue is the strategic/operational mix of projects. Many groups find that there are substantial opportunities in improving and supporting operating activities such as logistics and short-term planning. Satisfied clients come back for more and spread the word. This can result in opportunities for further work being generated fairly readily, although it can lead to a narrowing of focus of projects. Nevertheless, this can increase job security as operating areas of the organization come to rely on the OR group to maintain and upgrade key systems. However, in the long term this emphasis on operating decision support can make expansion of the project portfolio more difficult. It may also restrict appreciation of the total contribution made by OR, to the extent that satisfied clients are dispersed in particular functional areas with restricted high-level influence.

The undertaking of strategic projects may be desirable to build awareness of the real value of the OR function. Strategic projects imply involvement at senior levels of management, where issues may impact on many parts of the organization. Such work may be difficult to get and may involve a careful selection of precursor projects and negotiations over a long period, perhaps of years. The rewards in terms of building awareness and appreciation of the value of the OR function can be substantial. However, the risks can be no less substantial. Potential payoffs from OR involvement may be difficult to estimate in advance, yet involvement may be particularly timeconsuming into the bargain. Worse still, political and external factors may serve to obscure the perceived value of the OR contribution. Nevertheless, the scope for follow-on studies may substantially enhance job security and facilitate expansion of the OR function. 
The foregoing points are based on an interpretation of "effectiveness" as being the degree to which a contribution is made to organizational objectives. Apart from problems of measuring this contribution, this perspective implies careful choice of the project portfolio, with preference accorded to projects likely to generate the largest contribution to organizational objectives. For OR groups seeking to improve their effectiveness, this perspective is of limited assistance. What is needed is a deeper understanding of the processes involved in generating effective OR. This goes beyond effective analytical work in respect of individual projects, to effective management of the OR function as a whole. In this context a promising approach is to adopt a system perspective of the OR function and to examine a set of system needs which are prerequisites for success in the organization. For example, Georgopoulos (1973) has suggested the following basic needs which require attention:

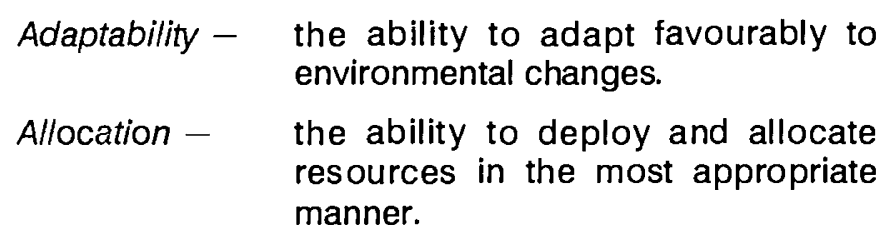
Allocation - the ability to deploy and allocate resources in the most appropriate manner.

Co-ordination - of energies and efforts to solve the system's problems.

Integration - securing co-operation and coherence, developing common values and mutual understanding.

Tension the ability to minimize and resolve management - tensions and conflicts.

Productivity - the ability to reach and maintain high levels of output: this involves the ability to maximize efficient and reliable performance.

Integrity - the ability of the system to preserve its identity and integrity as a distinct and unified problem-solving system.
A thoughtful examination of performance ought to take in these areas of concern. Given that this is a generic list of system needs, it is not applicable merely to an audit of the OR function. The list may also be useful in developing a systematic assessment of opportunities and scope for OR interventions throughout the organization.

The final item in the above list raises the question of the uniqueness of the OR contribution and the scenario raised earlier that OR work may be taken over by other parts of the organization. Often, in-house OR groups are in competition with other parts of the organization, either for resources or for work - particularly if management perceptions of what OR has to offer are unclear. Just as companies are exhorted in a competitive environment to identify core competences, so too should OR groups be. Prahalad and Hamel (1990) suggest three tests for identifying a core competence:

(1) it should provide potential access to a wide variety of markets;

(2) it should made a significant contribution to the perceived customer benefits of the organization's end-products; and

(3) it should be difficult for competitors to imitate.

Test 3 points to the identification and development by an OR group of competences which are unique within the organization. Prahalad and Hamel argue that these core competences are about harmonizing sources of technology, organizing work and the delivery of value. They could almost have been writing about OR!

STEPHEN WARD

\section{For the interested reader}

Georgopoulos, B.S. (1973): "An open system theory model for organisational research", in Neghandi, A. R. (Ed): Modern Organisation Theory, Kent State University Press, Ohio.

Prahalad, C.K. and Hamel, G. (1990): "The core competence of the corporation", Harvard Business Review, May-June, pp. 79-91. 